\title{
Interleukin 1 Administration in Mice Produces Hypoferremia Despite Neutropenia
}

\author{
Victor R. Gordeuk, Panju Prithviraj, Teresa Dolinar, and Gary M. Brittenham \\ Department of Medicine, Cleveland Metropolitan General Hospital, Cleveland, Ohio 44109; and School of Medicine, \\ Case Western Reserve University, Cleveland, Ohio 44106
}

\begin{abstract}
To determine whether the hypoferremic response to inflammation requires neutrophils, we administered human recombinant IL-1 to mice made neutropenic with cyclophosphamide. With single intraperitoneal injections of IL-1 the plasma iron concentrations decreased significantly in mice with either normal neutrophil counts or neutropenia. After single injections transferrin concentrations were not significantly changed, but the decrease in serum iron lowered mean transferrin saturations from a baseline of 45 to $24-30 \%$ in nonneutropenic mice, and from 99 to $70-77 \%$ in neutropenic mice. Similar changes were observed after intraperitoneal injections of Escherichia coli. 4-d continuous infusions of IL-1 also led to reductions in serum iron concentrations, but transferrin concentrations doubled. The combination of a decrease in serum iron and an increase in transferrin concentration after chronic infusion in neutropenic mice led to a greater decline in mean transferrin saturations, from a baseline of 110 to $25 \%$. In mice not given cyclophosphamide, chronic IL-1 infusion was associated with a reduction in mean hemoglobin concentrations from 14.7 to $13.5 \mathrm{~g} / \mathrm{dl}$, consistent with restricted availability of iron for erythropoiesis associated with low saturation of transferrin. We conclude that IL-1 can decrease the serum iron despite profound peripheral neutropenia and that transferrin is a positive acute phase reactant in the mouse.
\end{abstract}

\section{Introduction}

The pathway whereby the monokine IL-1 mediates the induction of hypoferremia in inflammation $(1,2)$ is unknown, but at least two general mechanisms have been proposed. One hypothesis is that lactoferrin released from neutrophils is responsible for the rapid transport of iron from plasma to hepatocytes and macrophages $(3,4)$. The second is that hypoferremia is produced by an impaired outflow of iron from reticuloendothelial cells, hepatocytes, and intestinal epithelial cells resulting from an altered intracellular handling of iron $(3,5)$. Evidence for the lactoferrin mechanism includes the following observations: (a) lactoferrin is contained within the specific granules of neutrophils $(6,7)$ which seem to be the primary source of circulating lactoferrin $(8,9)$; $(b)$ IL-1 leads to exocytosis of the contents of secondary granules with release of lactoferrin (10); (c) circulating lactoferrin may form lactoferriniron complexes (11) that are rapidly cleared from the plasma

Address correspondence to Dr. Victor R. Gordeuk, Cleveland Metropolitan General Hospital, 3395 Scranton Road, Cleveland, OH 44109.

Received for publication 29 December 1987 and in revised form 1 August 1988.

J. Clin. Invest.

(c) The American Society for Clinical Investigation, Inc. $0021-9738 / 88 / 12 / 1934 / 05 \$ 2.00$

Volume 82, December 1988, 1934-1938 by hepatocytes $(12,13)$, hepatic sinusoidal endothelial cells, Kupffer cells (14), and other macrophages $(11,15,16)$; and $(d)$ lactoferrin infusion produces hypoferremia in rats (11) and rabbits (4). Recently Goldblum and colleagues reported that induction of peripheral granulocytopenia in rats significantly reduced the percentage decline in serum iron between 0 and 6 $h$ after IL-1 injection. They concluded that "granulocyte released lactoferrin is a specific carrier molecule for transport and removal of iron during the acute phase response" (4).

Clinical observations, however, document the occurrence of inflammatory hypoferremia despite peripheral neutropenia. Low circulating lactoferrin concentrations are found during neutropenia $(8,17,18)$, and plasma lactoferrin is absent in agranulocytosis (19). Nonetheless, patients with neutropenia associated with nonmalignant conditions may have low plasma iron concentrations during inflammation (20), and patients undergoing bone marrow transplantation may substantially reduce the transferrin saturation during neutropenic febrile episodes (21). Leukemic patients with sepsis after intensive chemotherapy may develop hypoferremia despite neutropenia and low plasma lactoferrin concentrations (17).

To determine experimentally if circulating neutrophils are required for the hypoferremic response produced by IL-1 we examined the plasma iron after administration of human recombinant IL-1 to mice made neutropenic by treatment with cyclophosphamide.

\section{Methods}

$I L-1$. Human recombinant IL-1 was obtained from Dr. Peter Lomedico of Hoffman-La Roche (Nutley, NJ). The purification and biological characterization of this protein have been reported (22). This protein was prepared from Escherichia coli and consisted of the carboxy terminal 154 amino acids of the 271 amino acids of the human IL- 1 alpha precursor. Two lots of IL-1 were used in these investigations. (a) For analyzing the effect of an acute injection of IL-1 the preparation had a protein concentration of $60 \mu \mathrm{g} / \mathrm{ml}$ in $25 \mathrm{mM}$ Trizma $\mathrm{HCl}, 0.8 \mathrm{M}$ $\mathrm{NaCl}$ ( $\mathrm{pH} \mathrm{8.1)}$, and a specific activity of $3 \times 10^{7}$ lymphocyte activating factor (LAF) ${ }^{1}$ units/mg (23). There was slight contamination with endotoxin, 800 limulus amebocyte lysate units/ml (24). For this study IL-1 was diluted in $0.1 \%$ sera-saline (prepared using pooled mouse sera) to final concentrations of 600 and 6,000 LAF units/ml. (b) For examining the effect of a continuous infusion of IL-1, the preparation had a protein concentration of $500 \mu \mathrm{g} / \mathrm{ml}$ in $30 \mathrm{mM}$ Trizma $\mathrm{HCl}, 0.4$ $\mathrm{M} \mathrm{NaCl}$ (pH 7.8), and a specific activity of $1 \times 10^{9} \mathrm{D} 10$ units $/ \mathrm{mg}(25)$ (1 LAF unit $=20-50$ D10 units). Endotoxin content was minimal $(\sim 15$ limulus amebocyte lysate units/ml). For infusion the IL-1 was diluted in $0.1 \%$ sera-saline and placed in 2,001 or 2,002 mini-osmotic pumps (Alza Corp., Palo Alto, CA) that deliver at constant rates of 1 or $0.5 \mu \mathrm{l} / \mathrm{h}$.

Cyclophosphamide. Cyclophosphamide U. S. Pharmacopeia was obtained from Adria Laboratories (Columbus, $\mathrm{OH}$ ) and diluted in normal saline to a concentration of $2,000 \mu \mathrm{g} / \mathrm{ml}$ and injected intraperitoneally at a dose of $250 \mu \mathrm{g} / \mathrm{g}$ body wt.

1. Abbreviations used in this paper: LAF, lymphocyte activating factor. 
Trizma $\mathrm{HCl}$. Trizma $\mathrm{HCl}$ was obtained from Sigma Chemical Co. (St. Louis, MO) and diluted in $0.1 \%$ sera-saline for administration.

$E$. coli. Cultures of $E$. coli, A.T.C.C. No. 25922, were grown in tryptose phosphate broth overnight. The bacteria were washed three times in normal saline solution and resuspended in normal saline to a concentration of $2 \times 10^{7} \mathrm{CFU} / \mathrm{ml}$.

Mice. Male CF-1 mice weighing 25-35 g were obtained from Charles River Breeding Laboratories (Wilmington, MA). At the end of the study the animals were killed under light ether anesthesia by cardiac puncture and exsanguination. Blood was collected in heparinized syringes. White blood cell counts and hemoglobin concentrations were measured with a Coulter Counter ZF (Coulter Electronics, Inc., Hialeah, FL). Neutrophil counts were determined by differential counting of peripheral smears stained with Wright's stain and multiplication of the white blood cell count by the neutrophil fraction. Plasma iron concentrations and total iron binding capacities were determined using the methods of the International Committee for Standardization in Hematology $(26,27)$ modified for small quantities of plasma.

Single injection of $I L-1$. To determine the onset and duration of hypoferremia after single injections of IL-1, fasted normal mice were given intraperitoneal injections of $20 \mathrm{LAF}$ units $/ \mathrm{g} \mathrm{IL}-1$ or $1.2 \mu \mathrm{g} / \mathrm{ml}$ Trizma $\mathrm{HCl}$ in $0.1 \%$ sera-saline. Cohorts of five animals from each treatment group were killed at $1,2,4,6,8,10$, and $12 \mathrm{~h}$.

To examine the effect of IL-1 on neutropenic animals, cyclophosphamide or saline was administered intraperitoneally on days 1-3 to mice fed a low-iron diet obtained from ICN Nutritional Biochemicals (Cleveland, $\mathrm{OH}$ ). The mice were fasted from the evening of day 3 . On day 4 the mice were divided into four experimental groups with 10 mice in each group treated with cyclophosphamide and 10 treated with saline. At $0 \mathrm{~h}$ one group was injected intraperitoneally with $0.5 \mathrm{ml}$ Trizma $\mathrm{HCl}, 0.26 \mathrm{mg} / \mathrm{ml}$ in $0.1 \%$ sera-saline; a second group was given $10 \mathrm{LAF}$ units/g IL-1; a third group received $100 \mathrm{LAF}$ units/g IL-1; and a fourth group received $1 \times 10^{7} \mathrm{CFU} E$. coli in $0.5 \mathrm{ml}$ sterile saline. The animals were killed at $8 \mathrm{~h}$.

IL-1 infusion in mice not given cyclophosphamide. Osmotic pumps containing $0.16 \mathrm{mg} / \mathrm{ml} \mathrm{Trizma} \mathrm{HCl}$ in $0.1 \%$ sera-saline were implanted subcutaneously in five mice, and pumps containing IL-1 were implanted in six mice to provide $145 \mathrm{D} 10$ units/g per $\mathrm{h}$. The mice were killed after $94 \mathrm{~h}$.

$I L-1$ infusion in mice treated with cyclophosphamide. Osmotic pumps containing $3.8 \mu \mathrm{g} / \mathrm{ml}$ Trizma $\mathrm{HCl}$ in $0.1 \%$ sera-saline, or IL-1 to provide $14 \mathrm{D} 10$ units/g per $\mathrm{h}$, were implanted subcutaneously in nine mice. The concentration of IL-1 given to these animals was $\sim$ onetenth that given to mice not treated with cyclophosphamide. Cyclophosphamide was administered by subcutaneous injection daily for the first three days. The mice were killed on day 4, $99 \mathrm{~h}$ after the pumps were implanted.

Statistics. Independent sample $t$ tests were used to compare mean values for neutrophil counts, plasma iron concentrations, total iron binding capacities, and transferrin saturations. For multiple comparisons the Bonferroni procedure was used to assure detection of an overall significance level of $0.05(28,29)$.

\section{Results}

Onset and duration of hypoferremia after acute injection of $I L-1$. When compared with mice given Trizma $\mathrm{HCl}$ in $0.1 \%$ sera-saline, mice given IL-1 by acute injection experienced a significant reduction in mean plasma iron that began at $4 \mathrm{~h}$ and persisted through $8 \mathrm{~h}$ (Fig. 1). In subsequent studies we chose to examine the plasma iron concentration at $8 \mathrm{~h}$.

Acute injection of IL-1 in mice with and without cyclophosphamide treatment. Compared with mice injected with saline, mice treated with cyclophosphamide for $3 \mathrm{~d}$ developed leukopenia, elevated plasma iron concentrations, decreased total

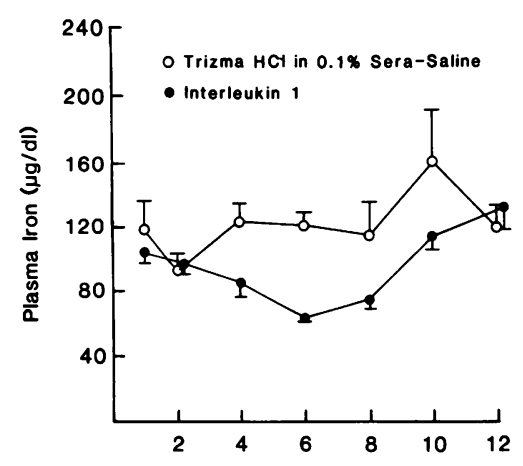

Figure 1. Effect of acute injection of $20 \mathrm{LAF}$ units/g human recombinant IL-1 on plasma iron concentration in mice. Each point represents mean \pm SEM value for five mice, except $n$ $=4$ at $1 \mathrm{~h}$ for mice given Trizma $\mathrm{HCl}$ in $0.1 \%$ sera-saline. Significance levels: $P<0.05$ at $4 \mathrm{~h}, P<0.001$ at $6 \mathrm{~h}$, $P<0.1$ at $8 \mathrm{~h}, P=\mathrm{NS}$

Time after Injection (Hours) for all other times.

iron binding capacities, and almost fully saturated transferrin (Table I).

When administered to mice treated with saline, IL-1 in concentrations of 10 and $100 \mathrm{LAF}$ units/g was associated with significant increases in neutrophils and significant decreases in plasma iron concentrations and transferrin saturations compared with mice injected with Trizma $\mathrm{HCl}$ in $0.1 \%$ sera-saline. There were no significant changes in total iron binding capacities. The decrease in plasma iron with $100 \mathrm{LAF}$ units/g IL-1 was significantly greater than that seen with $10 \mathrm{LAF}$ units/g IL-1. Injection of $1 \times 10^{7} \mathrm{CFU} E$. coli produced changes in white blood cells, plasma iron concentrations, and transferrin saturations similar to those seen with 100 LAF units/g IL-1, and a small increase in total iron binding capacity (Table I).

In mice that were neutropenic after cyclophosphamide treatment, IL-1 administration at both levels also resulted in significant decreases in plasma iron and transferrin saturations compared with injection of Trizma $\mathrm{HCl}$ in $0.1 \%$ sera-saline. There were also small but statistically significant increases in the neutrophil counts. Administration of $1 \times 10^{7} \mathrm{CFU}$ E. coli again produced changes in the parameters measured similar to the changes produced by 100 LAF units/g IL-1. Total iron binding capacities did not change significantly. $100 \mathrm{LAF}$ units/g IL-1 was associated with a higher mean neutrophil count and a lower mean transferrin saturation than was seen with $10 \mathrm{LAF}$ units/g, but there was no significant difference in the mean plasma iron concentrations.

The decrease in plasma iron was calculated for each of the animals treated with IL-1 and $E$. coli by subtracting the plasma iron concentration from the mean plasma iron concentration in the 8-h postinjection sample of the control group treated with Trizma $\mathrm{HCl}$ in $0.1 \%$ sera-saline. Mean values for decrease in plasma iron and mean absolute neutrophil counts are shown in Fig. 2. The mean decreases in plasma iron seen with administration of IL-1 and $E$. coli were significantly greater in the neutropenic animals when compared with animals without neutropenia $(P<0.001)$.

Continuous infusion of $I L-1$. In untreated mice given an IL-1 infusion for $4 \mathrm{~d}$ (Table II), results for mean plasma iron and white blood cells after completion of infusion were comparable to those seen $8 \mathrm{~h}$ after a single injection of IL-1 (Table I), with a significant increase in neutrophils and decrease in iron when compared with animals given infusion of Trizma $\mathrm{HCl}$ in $0.1 \%$ sera-saline. In contrast to the observations after the acute injection of IL-1, the total iron binding capacity doubled. The decline in mean transferrin saturation to $25 \%$ 


\begin{tabular}{|c|c|c|c|c|c|}
\hline Substance administered on day 4 & $n$ & Neutrophils & Serum iron & $\begin{array}{c}\text { Total iron } \\
\text { binding capacity }\end{array}$ & $\begin{array}{c}\text { Transferrin } \\
\text { saturation }\end{array}$ \\
\hline & & $10^{3} / \mu l$ & $\mu g / d l$ & $\mu g / d l$ & $\%$ \\
\hline \multicolumn{6}{|l|}{ Mice treated with normal saline days $1-3$} \\
\hline Trizma $\mathrm{HCl}$ in $0.1 \%$ sera-saline & 9 & $0.7 \pm 0.03$ & $128 \pm 7$ & $284 \pm 10$ & $45 \pm 2$ \\
\hline IL-1 (10 LAF units/g) & 9 & $1.6 \pm 0.1^{*}$ & $106 \pm 7^{\ddagger}$ & $317 \pm 10$ & $30 \pm 3^{*}$ \\
\hline IL-1 (100 LAF units/g) & 9 & $2.5 \pm 0.2^{*}$ & $75 \pm 4^{*}$ & $308 \pm 9$ & $24 \pm 1^{*}$ \\
\hline E. coli & 9 & $1.5 \pm 0.2^{*}$ & $88 \pm 7^{*}$ & $329 \pm 10^{\ddagger}$ & $27 \pm 3^{*}$ \\
\hline \multicolumn{6}{|c|}{ Mice treated with cyclophosphamide days $1-3$} \\
\hline Trizma $\mathrm{HCl}$ in $0.1 \%$ sera-saline & 9 & $0.2 \pm 0.1$ & $234 \pm 10$ & $236 \pm 11$ & $99 \pm 2$ \\
\hline IL-1 (10 LAF units/g) & 10 & $0.5 \pm 0.03^{\ddagger}$ & $162 \pm 7^{*}$ & $215 \pm 6$ & $77 \pm 2^{*}$ \\
\hline IL-1 (100 LAF units/g) & 7 & $0.3 \pm 0.04$ & $157 \pm 3^{*}$ & $223 \pm 9$ & $70 \pm 2^{*}$ \\
\hline E. coli & 8 & $0.5 \pm 0.04$ & $150 \pm 7^{*}$ & $216 \pm 5$ & $69 \pm 3^{*}$ \\
\hline
\end{tabular}

Represents day 4 values, mean \pm SEM. Significance level when compared with value for mice treated with Trizma $\mathrm{HCl}$ in $0.1 \%$ sera-saline: ${ }^{*} P$ $<0.01 ;{ }^{\ddagger} P<0.05$.

with continuous infusion of IL-1 was greater than the decrease to 70 and $77 \%$ after acute injection of IL-1.

In a separate experiment, mice made neutropenic by cyclophosphamide treatment received IL-1 infusion for $99 \mathbf{h}$. These mice experienced a significant decrease in plasma iron and doubling of the total iron binding capacity when compared with animals that were given infusion of Trizma $\mathrm{HCl}$ in $0.1 \%$ sera-saline. There was no significant difference in white blood cell counts between the mice given IL-1 and those given Trizma $\mathrm{HCl}$ in $0.1 \%$ sera-saline.

In the mice not treated with cyclophosphamide, IL-1 infusion for $4 \mathrm{~d}$ significantly lowered hemoglobin concentration (Table II). The decrease in hemoglobin concentration in these mice was similar to that seen with cyclophosphamide treatment.

\section{Discussion}

Human recombinant IL-1 administration by either acute injection or chronic infusion significantly decreased plasma iron concentrations in mice with either normal neutrophil counts

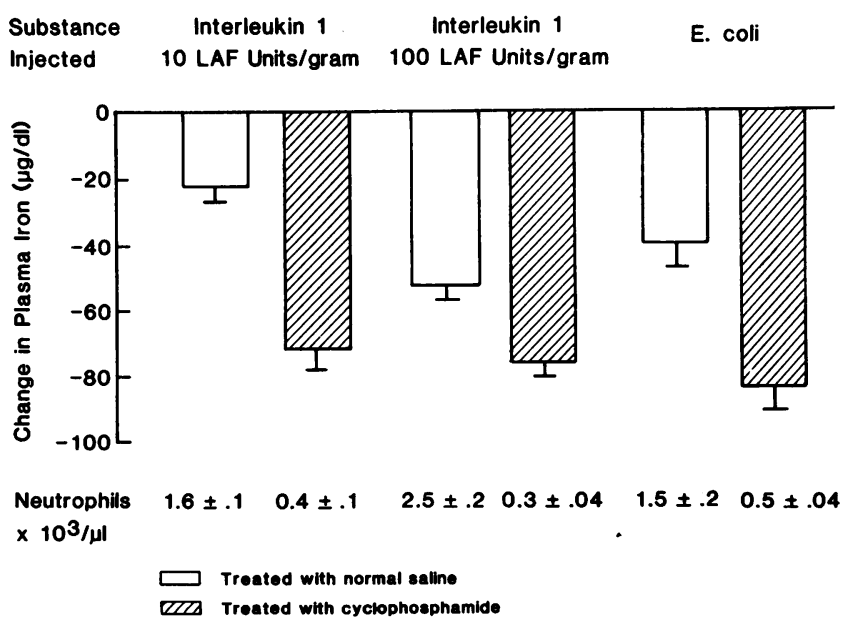

Figure 2. Mean \pm SEM decrease in plasma iron observed with acute injection of IL-1 and $E$. coli in neutropenic and normal mice. Significance levels: $P<0.001$ for each comparison. or severe neutropenia resulting from cyclophosphamide treatment. Similar findings were observed with injection of $E$. coli, possibly due to endogenous release of IL-1. Thus, our results suggest that factors other than release of lactoferrin by neutrophils may be involved in the hypoferremic effect of IL-1 and that further consideration should be given to impaired flow of iron from tissues to plasma as the explanation for hypoferremia in inflammation.

Administration of IL-1 over $4 \mathrm{~d}$ by continuous infusion via subcutaneously implanted osmotic pumps permitted an approximation of physiologic conditions. In contrast to acute injection, the continuous infusion of IL-1 produced a marked rise in transferrin concentration as measured by total iron binding capacity (Table II). This increase in transferrin concentration in mice after prolonged IL-1 infusion contrasts with the decrease in transferrin concentration found in humans with chronic inflammation (30).

There are considerable interspecies differences in the details of iron metabolism and the acute phase response $(31,32)$. The plasma iron concentration in iron-replete mice is typically two or more times that in iron-replete humans. Mice transferrin concentrations are also higher (33). Transferrin is a negative acute phase reactant in man and a positive acute phase reactant in rabbits $(32,34)$. IL- 1 stimulates cultured rabbit hepatocytes to synthesize transferrin (34). Our results suggest that chronic infusion of IL-1 stimulates transferrin synthesis in mice (Table II). In rabbits the serum transferrin concentration does not increase until $24 \mathrm{~h}$ after an inflammatory stimulus but then continues to increase for up to $72 \mathrm{~h}$ (34). Our observations in mice are consistent with these observations in rabbits. The transferrin concentration as measured by total iron binding capacity was not increased by $8 \mathrm{~h}$ after an acute injection of IL-1 (Table I) but the level doubled with $4 \mathrm{~d}$ of continuous IL-1 infusion (Table II). Thus, during inflammation humans and mice are similar in that both experience decreased plasma iron concentrations and transferrin saturations. They differ in that the transferrin concentration decreases in man but increases in mice. Because of interspecies differences in the metabolism of iron, caution is needed in extrapolating from these experimental results in mice to humans.

Cyclophosphamide-treated, neutropenic mice had a lower mean transferrin saturation $(25 \%)$ after chronic infusion of 
Table II. 4-d Infusion of IL-1 in Mice

\begin{tabular}{|c|c|c|c|c|c|c|}
\hline Substance infused by osmotic pumps & $n$ & Neutrophils & Serum iron & $\begin{array}{c}\text { Total iron } \\
\text { binding capacity }\end{array}$ & $\begin{array}{l}\text { Transferrin } \\
\text { saturation }\end{array}$ & Hemoglobin \\
\hline & & $10^{3} / \mu l$ & $\mu g / d l$ & $\mu g / d l$ & $\%$ & $g / d l$ \\
\hline \multicolumn{7}{|l|}{ Mice not given cyclophosphamide } \\
\hline Trizma $\mathrm{HCl}$ in $0.1 \%$ sera-saline & 5 & $1.2 \pm 0.2$ & $210 \pm 8$ & $321 \pm 16$ & $66 \pm 3$ & $14.7 \pm 0.3$ \\
\hline IL-1 (145 D10 units/g per h) & 6 & $8.5 \pm 1.8$ & $142 \pm 13$ & $633 \pm 18$ & $22 \pm 2$ & $13.5 \pm 0.2$ \\
\hline$P$ & & $<0.01$ & $<0.001$ & $<0.001$ & $<0.001$ & $<0.01$ \\
\hline \multicolumn{7}{|c|}{ Mice treated with cyclophosphamide days $1-3$} \\
\hline Trizma $\mathrm{HCl}$ in $0.1 \%$ sera-saline & 5 & $0.1 \pm 0.04$ & $342 \pm 53$ & $318 \pm 21$ & $110 \pm 21$ & $13.6 \pm 0.4$ \\
\hline IL-1 (14 D10 units/g per h) & 4 & $0.1 \pm 0.1$ & $172 \pm 15$ & $700 \pm 30$ & $25 \pm 2$ & $13.5 \pm 0.5$ \\
\hline$P$ & & NS & $<0.05$ & $<0.001$ & $<0.01$ & NS \\
\hline
\end{tabular}

Represents day 4 values, mean \pm SEM.

IL-1 than after a single injection (mean transferrin saturations $70-77 \%$ ) because of the increase in transferrin concentration with chronic infusion. The magnitudes of the declines in serum iron concentrations were similar in both forms of administration (Tables I and II). Thus, with chronic IL-1 infusion in mice both the decline in serum iron and the increase in transferrin concentration contributed to a reduction in transferrin saturation to a level substantially below normal. The mechanisms responsible for the acute hypoferremia observed after administration of IL-1 remain to be determined. With acute inflammation, a rapid decrease in the flow of iron from reticuloendothelial cells is observed that has been attributed to altered intracellular handling of iron (3). Konijn and Hershko have provided indirect evidence that inflammation provides a direct stimulus to apoferritin synthesis with subsequent diversion of iron away from the release pathway into ferritin stores (5), an action that could conceivably be mediated by IL-1. As yet, the effect of IL-1 on apoferritin synthesis has not been examined, and the role of apoferritin synthesis in the production of acute hypoferremia awaits direct confirmation.

Iron uptake by tissues is directly related to transferrin saturation (35). Monoferric transferrin, which predominates with low transferrin saturations, delivers iron to the tissues less than one-fifth as efficiently as the diferric transferrin that is prevalent at high transferrin saturations (36). The low transferrin saturation with IL-1 infusion may have a physiologic role in restricting the availability of iron for erythropoiesis, as manifested by a significant reduction in hemoglobin concentration on day 4 in the mice not given cyclophosphamide (Table II). This finding resembles the change seen in the anemia of chronic disease in humans where iron release from reticuloendothelial cells is impaired and iron-deficient erythropoiesis results (30). Our observations are consistent with the hypothesis that IL-1 mediates the anemia of chronic disease (3). The decrease in hemoglobin concentration in mice given IL-1 was similar to that observed in mice with marrow suppression produced by cyclophosphamide (Table II).

The human recombinant IL-1 used in this study was highly purified (22) and it is unlikely that a hitherto unrecognized contaminant was responsible for the effects observed. The amounts of endotoxin present in the two preparations of IL-1 were less than concentrations that increase fibrinogen (37), produce leukocytosis (38), or decrease plasma iron (39). The validity of testing human recombinant IL-1 in mice is sup- ported by previous studies that examined the effect of human recombinant IL-1 on plasma iron in mice and used the heat inactivated protein for control purposes (40). Although only circulating neutrophils were measured in our study, it is unlikely that lactoferrin derived from any remaining neutrophilic forms in the bone marrow and spleen could account for the observed hypoferremia.

The conclusion of Goldblum and colleagues that the development of hypoferremia after injection of IL-1 was blunted in rats made neutropenic by cyclophosphamide treatment (4) may differ from our findings because of the manner of data interpretation. Goldblum et al. expressed changes in serum iron as a percentage of baseline values. This method of analysis may not be optimal because of the effect that neutrophil depletion with cyclophosphamide would be expected to have on serum iron concentrations. A variety of cancer chemotherapy agents regularly produce a rise in the plasma iron concentrations (41) as observed in this study (Tables I and II). With an elevated basal plasma iron concentration in neutropenic animals, a smaller percentage decrease in plasma iron may represent an equivalent or larger absolute decrease in plasma iron when compared with control animals with a normal iron concentration. In our study the absolute declines in iron concentrations observed after acute injections of IL- 1 and $E$. coli were greater in the neutropenic, hyperferremic animals than in those with normal neutrophil counts (Fig. 2).

We have shown that single injections of human recombinant IL-1 in mice with normal circulating neutrophil counts or severe neutropenia produce significant reductions in plasma iron concentrations and transferrin saturations. Chronic administration of IL-1 leads to lowered plasma iron levels, a twofold rise in transferrin concentrations, and a further lowering of transferrin saturations. With chronic IL-1, hemoglobin concentrations decrease consistent with restricted availability of iron for erythropoiesis associated with low saturation of transferrin. We conclude that IL-1 can decrease serum iron despite profound peripheral neutropenia, and that transferrin is a positive acute phase reactant in the mouse.

\section{Acknowledgments}

We wish to thank Patricia Rybicki, Cindy Moore, and Judi Minium for their technical assistance, and Joyce Rusnak for preparing the manuscript. 
This investigation was supported by Public Health Service grant P30CA43703 awarded by the National Cancer Institute, Department of Health and Human Services.

\section{References}

1. Kampschmidt, R. F., and H. Upchurch. 1969. Lowering of plasma iron concentration in the rat with leukocyte extracts. Am. $J$. Physiol. 216:1287-1291.

2. Klasing, K. C. 1984. Effect of inflammatory agents and interleukin 1 on iron and zinc metabolism. Am. J. Physiol. 247 (Regulatory Integrative Comp. Physiol. 16):R901-R904.

3. Lee, G. R. 1983. The anemia of chronic disease. Semin. Hematol. 20:61-80.

4. Goldblum, S. E., D. A. Cohen, M. Jay, and C. J. McClain. 1987. Interleukin 1-induced depression of iron and zinc: role of granulocytes and lactoferrin. Am. J. Physiol. (Endocrinol. Metab. 15):E27-E32.

5. Konijn, A. M., and C. Hershko. 1977. Ferritin synthesis in inflammation. I. Pathogenesis of impaired iron release. Br. J. Haematol. 37:7-16.

6. Baggiolini, M., C. DeDuve, P. L. Masson, and J. F. Heremans. 1970. Association of lactoferrin with specific granules in rabbit heterophil leukocytes. J. Exp. Med. 131:559-570.

7. Klempner, M. S., C. A. Dinarello, and J. I. Gallin. 1978. Human leukocyte pyrogen induces release of specific granule contents from human neutrophils. J. Clin. Invest. 61:1330-1336.

8. Hansen, N. E., J. Malmquist, and J. Thorell. 1975. Plasma myeloperoxidase and lactoferrin measured by radioimmunoassay: relations to neutrophil kinetics. Acta Med. Scand. 198:437-443.

9. Olofsson, T., I. Olsson, P. Vengel, and B. Edgefors. 1977. Serum myeloperoxidase and lactoferrin in neutropenia. Scand. J. Haematol. 18:73-80.

10. Smith, B. J., S. C. Speziale, and B. J. Bowman. 1985. Properties of interleukin-1 as a complete secretagogue for human neutrophils. Biochem. Biophys. Res. Commun. 130:1233-1240.

11. Van Snick, J. L., P. L. Masson, and J. F. Heremans. 1974. The involvement of lactoferrin in the hyposideremia of acute inflammation. J. Exp. Med. 140:1068-1084.

12. Prieels, J. P., S. V. Pizzo, L. R. Glascow, J. C. Paulson, and R. L. Hill. 1978. Hepatic receptor that specifically binds oligosaccharides containing fucosyl, ${ }^{3} \mathrm{~N}$-acetylglucosamine linkages. Proc. Natl. Acad. Sci. USA. 75:2215-2219.

13. Regoeczi, E., P. A. Chindemi, M. T. Debanne, and J. P. Prieels. 1985. Lactoferrin catabolism in the rat liver. Am. J. Physiol. 248 (Gastrointest. Liver Physiol. 11):G8-G14.

14. Courtoy, P. J., N. Moguilevsky, L. A. Retegui, C. E. Castracane, and P. L. Masson. 1984. Uptake of lactoferrin by the liver. II. Endocytosis by sinusoidal cells. Lab. Invest. 50:329-334.

15. Van Snick, J. L., B. Markowetz, and P. L. Masson. 1977. The binding of human lactoferrin by mouse peritoneal macrophages and the transfer of its iron into ferritin. J. Exp. Med. 146:817-827.

16. Van Snick, J. L., and P. L. Masson. 1976. The binding of human lactoferrin to mouse peritoneal cells. J. Exp. Med. 144:15681580 .

17. Baynes, R., W. Bezwoda, T. Bothwell, Q. Khan, and N. Mansoor. 1986. The non-immune inflammatory response: serial changes in plasma iron, iron binding capacity, lactoferrin, ferritin, and C-reactive protein. Scand. J. Clin. Lab. Invest. 46:695-704.

18. Lash, J. A., T. D. Coates, J. Lafuse, R. L. Baehner, and L. A. Boxer. 1983. Plasma lactoferrin reflects granulocyte activation in vivo. Blood. 61:885-888.

19. Bennett, R. M., and T. Kokocinski. 1978. Lactoferrin content of peripheral blood cells. Br. J. Haematol. 39:509-521.

20. Dancey, J. T., and L. J. Brubaker. 1982. Neutrophil marrow cellularity in neutropenia. Am. J. Hematol. 12:309-322.
21. Hunter, R. L., B. Bennett, M. Towns, and W. R. Volger. 1984. Transferrin in disease. II. Defects in the regulation of transferrin saturation with iron contribute to susceptibility to infection. Am. J. Clin. Pathol. 81:748-753.

22. Grubler, U., A. Q. Chua, A. S. Stern, C. P. Hellman, M. P. Vitek, T. M. Dechiara, W. R. Benjamin, K. J. Collier, M. Dukovich, P. C. Familetti, et al. 1986. Recombinant human interleukin 1: purification and biological characterizations. J. Immunol. 136:2492-2497.

23. Mizel, S. B., J. J. Oppenheim, and D. L. Rosenstreich. 1978. Characterization of lymphocyte-activating factor (LAF) produced by the macrophage cell line P388D1. J. Immunol. 120:1497-1503.

24. Levin, J. 1982. The limulus test and bacterial endotoxins: some perspectives. In Endotoxins and their Detection with the Limulus Amebocyte Lysate Test. S. W. Watson, W. J. Levin, and T. J. Novitsk, editors. Alan R. Liss, Inc., New York. 7-24.

25. Kaye, J., S. Procelli, J. Tite, B. Jones, and C. A. Janeway. 1983. Both a monoclonal antibody and antisera specific for determinants unique to individual cloned helper T-cell lines can substitute for antigen and antigen-presenting cells in the activation of T-cells. J. Exp. Med. 158:836.

26. International Committee for Standardization in Hematology (Iron Panel). 1978. Recommendations for measurement of serum iron in human blood. Br. J. Haematol. 38:291-294.

27. International Committee for Standardization in Hematology (Iron Panel). 1978. The measurement of total and unsaturated ironbinding capacity in serum. Br. J. Haematol. 38:281-287.

28. Winer, B. J. 1971. Statistical Principles in Experimental Design. McGraw Hill, Inc., New York. Second ed. 907 pp.

29. Miller, R. G. 1981. Simultaneous Statistical Inference. Springer-Verlag New York, Inc., New York. Second ed. 299 pp.

30. Cartwright, G. E., and G. R. Lee. 1971. The anaemia of chronic disorders. Br. J. Haematol. 21:147-152.

31. Lozoff, B., and G. M. Brittenham. 1986. Behavioral aspects of iron deficiency. Prog. Hematol. XIV:23-53.

32. Kushner, I., and A. Mackiewicz. 1987. Acute phase proteins as disease markers. Disease Markers. 5:1-11.

33. Bannerman, R. M. 1983. Hematology. In The Mouse in Biomedical Research. Vol. III. Normative Biology, Immunology and Husbandry. H. L. Foster, J. D. Small, and J. G. Fox, editors. Academic Press, Inc., New York. 293-309.

34. Mackiewicz, A., M. K. Ganapathi, D. Schultz, D. Samols, J. Reese, and I. Kushner. 1988. Regulation of rabbit acute phase protein biosynthesis by monokines. Biochem. J. 253:851-857.

35. Cazzola, M., H. A. Huebers, M. H. Sayers, P. MacPhail, M. Eng, and C. A. Finch. 1985. Transferrin saturation, plasma iron turnover, and transferrin uptake in normal humans. Blood. 66:935-939.

36. Huebers, H. A., E. Csiba, E. Huebers, and C. A. Finch. 1985. Molecular advantage of diferric transferrin in delivering iron to reticulocytes: a comparative study. Proc. Soc. Exp. Biol. Med. 179:222-226.

37. Wycoff, H. D. 1970. Production of fibrinogen following an endotoxin injection. Proc. Soc. Exp. Biol. Med. 133:940-943.

38. Kampschmidt, R. F., and H. F. Upchurch. 1980. Neutrophil release after injection of endotoxin or leukocytic endogenous mediator in rats. J. Reticuloendothel. Soc. 28:191-201.

39. Kampschmidt, R. F., and H. F. Upchurch. 1962. Effects of bacterial endotoxin on plasma iron. Proc. Soc. Exp. Biol. Med. 110:191-193.

40. Dinarello, C. A., J. G. Cannon, J. W. Mier, H. A. Bernheim, G. LoPreste, D. L. Lynn, R. N. Love, A. C. Webb, P. E. Auron, R. C. Reuben, et al. 1986. Multiple biological activities of human recombinant interleukin 1. J. Clin. Invest. 77:1734-1739.

41. Gordeuk, V. R., G. M. Brittenham, G. D. McLaren, and P. J. Spagnuolo. 1986. Hyperferremia in immunosuppressed patients with acute nonlymphocytic leukemia and the risk of infection. J. Lab. Clin. Med. 108:466-472. 